\title{
Kentleşme ve Ekonomik Büyümenin Çevresel Bozulmaya Etkisi: Türkiye Örneği
}

\author{
DOI: 10.26466/opus.725429
}

*

\author{
Nurullah Altıntaș * \\ * Dr. Öğr. Üyesi Sakarya Üniversitesi SBF, İktisat Bölümü, Sakarya \\ E-Posta: naltintas@sakarya.edu.tr \\ ORCID: $\underline{0000-0001-9425-3516}$
}

\section{Öz}

Bu çalışmada 1960-2014 döneminde, Türkiye'de ekonomik büyüme ve kentleşmenin çevresel bozulma üzerine etkileri ele alınmıştır. Bunu yaparken ARDL Sınır Testi ve ECM'ye dayalı Granger Nedensellik testi kullanılmıştır. Elde edilen sonuçlara göre Türkiye'de bu dönem içinde kentleşme hem kısa dönemde hem de uzun dönemde $\mathrm{CO} 2$ emisyonunu artırmaktadır. Bununla birlikte ekonomik büyümenin ilk dönemlerinde çevresel bozulma artarken, belli bir seviyeden sonraki büyüme çevresel bozulma üzerinde azaltıcı bir etkiye sahiptir. Bu durum Türkiye'de Çevresel Kuznet Ĕ̆risinin varlı̆̆ını doğrulamaktadır. Elde edilen sonuçlar Ekolojik Modernleşme, Kentsel Geçiş ve Kompakt Şehir teorileri dikkate alınarak değerlendirilmektedir. Buna göre söz konusu dönem içinde Türkiye'de Kompakt Şehir teorisinin şartlarının ampirik olarak kanıtlanmadığı görülürken, Kentsel Geçiş teorilerinde yer alan çevresel sorunların yer aldiğına işaret edilmektedir. Kentleşmenin çevresel bozulmaya neden olan yönleri dikkate alınarak politika önerileri getirilmektedir. Bu bağlamda öncelikle hanehalkı bilinçlendirilmeli, planlı ve organize kentleşme stratejisi ortaya konmalıdır. Çevre dostu malları üretimi ve tüketimi teşvik edilmeli, gerektiğinde sübvanse edilmelidir. Özellikle ölçek ekonomilerinden faydalanılacak biçimde ulaşım hizmetleri sağlanmalıdır.

Anahtar Kelimeler: Kentleşme, Ekonomik Büyüme, EKC, Ekolojik Modernleşme Teorisi 


\title{
Impact of Economic Growth And Urbanization on Environmental Degradation: Evidence From Turkey
}

\begin{abstract}
In this study, during 1960-2014, the effects of economic growth and urbanization on environmental degradation in Turkey were discussed. While doing this, ARDL Limit Test and ECM based Granger Causality Test were used. According to the results, urbanization increases CO2 emission both in the short term and long term in Turkey. However, while environmental degradation increases in the early stages of economic growth, growth after a certain level has a reducing effect on environmental degradation. This confirms the existence of Environmental Kuznets Curve in Turkey. The results obtained are evaluated by considering the Ecological Modernization, Urban Transition and Compact City theories. According to the terms of the compact city, theory is seen in Turkey in the period in question have not been proven empirically, located in Urban Transition theory it is pointed out that the environmental issues involved. Policy suggestions are brought into consideration by considering the aspects of urbanization causing environmental degradation. In this context, firstly, household awareness should be raised and a planned and organized urbanization strategy should be put forward. Production and consumption of environmentally friendly goods should be encouraged and subsidized if necessary. Particularly, transportation services should be provided in such a way that benefits from economies of scale are possible
\end{abstract}

Keywords: Urbanization, Economic Growth, EKC, Ecological Modernization Theory 


\section{Giriş}

Kentleşme hem gelişmekte olan ülkelerde hem de gelişmiş ülkelerde artış gösteren ve ekonomiyi etkileyen temel konulardan biri olarak karşımıza çıkmaktadır. Türkiye'de 1960'lardan günümüze geldiğimizde kentleşme oranının yüzde otuzdan yüzde yetmiş beş seviyesine geldiği görülmektedir. Kentleşme oranındaki bu artışın ardında daha iyi eğitim talebi, iş imkânı, daha imkânlı sağlık koşullarının varlı̆̆ı ve refah isteği vardır. Bununla birlikte, kentleşmedeki artıs ekonomi genelinde kaynak kullanımını ve çevre koşullarını etkileyebilmektedir. Kentleşmeyle birlikte kentsel alanların fiziksel olarak gelişmesi ve genişlemesine yol açan ekonomik ve sosyal bir dönüşüm gerçekleşmektedir. Sadece nüfus kırsal alanlardan kentsel şehirlere kaymakla kalmaz, aynı zamanda tarımsal ekonomiden sanayi tabanlı ekonomiye dönüşümü de beraberinde getirir (Aydın ve Belli, 2018: 110). Bu durumun özellikle ekonomik büyüme, enerji tüketimi, işsizlik ve çevresel bozulma gibi alanları etkilediği bilinmektedir. Kentleşme neticesinde artan enerji talebi ve sonrasında hava kirliliği, orman alanlarındaki azalma, su kirliliği gibi çevresel bozulmaya götüren bir süreç oluşabilmektedir. Kentlerde planlama eksikliği ve yönetim bozuklukları durumunda çevresel koşulların üzerinde olumsuz etki bırakacağı aşikârdır. Diğer taraftan özellikle refah seviyesinin yükselmesi ile birlikte dinamik olarak ekonomilerde çevresel bilinçte farkındalık, devletin katı çevre politikaları, teknolojide ilerleme ve çevre dostu teknoloji ile birlikte çevresel bozulmada iyileşme beklenmektedir.

Kentleşme ile çevresel bozulma ilişkisi, ekolojik modernleşme, kentsel çevre geçişi ve kompakt şehir teorileri üzerinden açılanmaktadır. Ekolojik modernleşme teorisine göre sadece ekonomik değişim değil aynı zamanda toplumsal ve kurumsal değişimler de dikkate alınarak modernleşmenin çevre üzerindeki etkileri incelenir. Bu teoride kentleşme, modernleşmenin önemli bir göstergesi olarak kabul edilen toplumsal dönüşüm sürecidir. Kalkınmanın başlangıç ve orta aşamasına kadar çevresel bozulmanın artabileceği bununla birlikte, toplumlarda çevresel sürdürülebilirliğin önemi ve bu konudaki bilinç oluştukça, teknolojik yenilikler ve bilgi ve hizmet temelli endüstrilere geçiş yoluyla çevresel etkileri ekonomik büyümeden ayırmaya çalıştıkça, daha fazla modernizasyon çevresel sorunları en aza indirebilir (Belli ve Aydın, 2017, s.423-424). Sonuç olarak kalkınmanın ilerleyen aşamasında 
çevresel sürdürülebilirlik ekonomik büyümeye tercih edilebilirken, diğer taraftan büyüme hedefi çevresel sürdürülebilirlik dişlanmadan gerçekleştirilmektedir (Mol ve Spaargaren 2000, s.19; Poumanyvong ve Kaneko 2010, s.435). Kentsel çevre geçiş teorisi temel olarak kentsel çevre sorunlarının türlerini ve evrimini tartışmaktadır. Kentsel çevre sorunlarının ekonomik kalkınma aşamalarına göre değiştiğini göstermektedir. Kalkınmanın ilk aşamalarında yoksullukla ilgili temiz su ve yetersiz sanitasyon gibi çevresel sorunlarla karşı karşıyadır. Gelir seviyesindeki artışla birlikte bu sorunlar azalırken yerine endüstriyel kirlilikle ilgili su ve hava kirliliği gibi sorunlarla karşılaşılmakla birlikte artan refahın etkisiyle zengin şehirlerde genellikle tüketim ile ilgili çevre sorunları meydana gelmektedir. Zengin şehirlerin tüketim kalıpları ve yaşam biçimleri, düşük gelirli şehirlerinkinden daha fazla kaynak yoğundur. Şehirler zenginleştikçe kentsel altyapı, ulaşım ve bireysel kaynak tüketimi talepleri de artmaktadır. Böylece, enerji tüketimi ve CO2 emisyonları gibi tüketim ile ilgili konular daha belirgin hale gelmektedir. Bu sorunlar her aşamada farklılaşmakla birlikte keskin ayrımlar söz konusu değildir (Poumanyvong ve Kaneko 2010, s.435; Adams ve Klobodu 2017, s.1037;Sadorsky 2014, s.152).

Kompakt şehir teorisindeki temel ilke, konut, işyeri ve dükkânların birleşimi ile şehir merkezine yakın ya da şehir içi yüksek yoğunluklu gelişimdir. $\mathrm{Bu}$ durum yarı müstakil ve çok aileli konutları içerirken; tek aileli konutları dışlar. Ayrıca bu teori, konut için düşük enerji kullanımı, verimli uzaktan ısıtma sistemi, kamu ve özel hizmetlere yakınlık ile oldukça teknolojik ulaşım sistemi gibi sürdürülebilir enerji kullanımını destekleyen, düşük karbona neden olan bu özellikleri vurgulamaktadır. Kompakt şehir için temel gerekçe, en az enerji yoğun aktivite modelleriyle sonuçlanmış olması ve bu şekilde küresel ısınma problemlerine karşı koymamıza destek olmasıdır (Holden ve Norland 2005, s.2148).

$\mathrm{Bu}$ çalışmada kentleşmedeki artış neticesinde çevresel bozulmanın durumu sorgulanmaktadır. Bununla birlikte ekonomideki büyüme beraberinde çevreyi nasıl etkilemektedir sorusuna cevap aranmaktadır. Türkiye ekonomisinde bir bütün olarak kentleşme ve ekonomik büyümenin çevresel bozulmaya olan etkisi 1960-2014 dönemi için ekonometrik yöntem ile tartışlacaktır. Elde edilen sonuçlar üzerinden kentleşme-çevresel bozulma teorilerinin Türkiye'deki geçerliliği sorgulanmaktadır. Bu anlamda hem uygulamalı hem 
de teorik boyutu birlikte değerlendirmeye tabi tutulmuştur. Elde edilen sonuçlar ışığında politika önerileri getirilmiştir. Çalışma bu giriş bölümünün ardından uygulamalı literatür, metodoloji ve ampirik sonuçlar ile devam ederken sonuç ve politika önerileri ile tamamlanacaktır.

\section{Uygulamalı Literatür Taraması}

Kentleşme çevresel bozulma uygulamalı literatürü incelendiğinde elde edilen sonuçlar açısından bir mutabakat olmadığı görülmektedir. Buna göre çalışmaların dört ayrı grupta toplandığı görülmektedir. Bunlardan ilki kentleşmenin çevresel bozulmayı azalttığı çalışmalar, ikinci olarak kentleşmenin çevresel bozulmayı artırdığı çalışmalar ve üçüncü olarak da kentleşme ile çevresel bozulma arasında doğrusal olmayan ilişkinin varlığını bulan çalışmalardır. Son olarak da bu grupların dışında değişkenler arasındaki ilişkinin anlamsız olduğunu bulan çalışmalara da rastlanmaktadır.

Birinci gruptaki çalışmalardan Ali, Abdul-rahim ve Ribadu (2017) nüfusun tamamının kentlerde yaşadığı Singapurda 1970-2015 döneminde kentleşmenin $\mathrm{CO} 2$ emisyonu üzerindeki ilişkiyi incelemişlerdir. Elde edilen sonuca göre kentleşmenin çevresel bozulma üzerinde azaltıc ve önemli bir etkisi olduğuna ulaşılmıştır. Dolayısıyla, ülkedeki çevresel bozulmayı azaltmak için kullanılacak politikalar başlatılırken kentleşme bir engel olarak görülmeyecektir. Azam ve Khan (2015) Bangladeş, Hindistan, Pakistan ve Sri Lanka için 1982-2013 dönemi verileri ile En Küçük Kareler Metodu kullanılarak incelenmiştir. Elde edilen sonuçlar açısından kentleşmenin çevresel bozulma üzerindeki azaltıcı etkisi Hindistan ve Bangladeş için doğrulanmıştır. Saidi ve Mbrak (2016), finansal gelişme, ticaret, büyüme ve kentleşmenin CO2 emisyonu üzerindeki etkisini Gelişmekte Olan 19 ülke için araştırmıştır. GMM-SYS analizinin kullanıldığı çalışma 1990-2013 dönemini kapsamaktadır. Kentleşmedeki \%1'lik bir artışın karbon emisyonunu yaklaşık \%0.4 azalttığı sonucuna ulaşılmıştır. Buna göre kentleşmenin çevresel politikalar açısından olumsuz etkilerinin baskın olmadığı anlaşılmıştır.

İkinci gruptaki çalışmalardan Salahuddin vd. (2001) Güney Afrika' da küreselleşme ve kentleşmenin CO2 emisyonu üzerindeki etkisini ARDL Sınır testi yöntemiyle 1984-2016 dönemi için incelemiştir. Analiz sonuçları kentleşmenin hem uzun vadede hem de kısa vadede $\mathrm{CO} 2$ emisyonlarını uyardığını göstermektedir. Hem kısa vadede hem de uzun vadede bu etkiler istatistiksel 
olarak anlamlıdır, sonuçların kentsel çevre geçiş teorisini desteklediği ifade edilmektedir. Güney Afrika gibi büyüyen bir ekonomi için, kentleşmenin h1zının yavaşlatılması çevre bozulmasını azaltmak veya dengelemek için uygun bir seçenek olamayacağından, kentleşmeye bağlı bu tür emisyonları hafifletmenin potansiyel bir yolu planlı ve organize bir kentleşme önerilmektedir. Shahbaz vd. (2014) tarafından Birleşik Arap Emirliklerini konu alan çalı̧̧malarında 1975-2011 döneminde yapısal kırılmaları dikkate alan ARDL yöntemi kullanılmıştır. Kentleşmedeki yükseliş trendi konut yapımı, sanayileşme ve sağlık tesisleri için baskı yaratmaktadır. Bu baskı neticesinde $\mathrm{CO} 2$ emisyonunda artış ortaya çıkmaktadır. Küresel bir turizm merkezi haline gelmek için gelişmiş bir altyapı oluşturmak üzere sıfırdan inşa edilecek büyük inşaat projelerinin hava kirliliğini büyük ölçüde artırdığı vurgulanmıştır. Destek ve Özsoy (2015) Türkiye'de 1970-2010 döneminde enerji tüketimi, ekonomik küreselleşme ve kentleşmenin çevre üzerindeki etkisini ARDL yöntemi ile incelemiştir. Buna göre kentleşmenin kısa dönemde çevresel bozulma üzerindeki etkisi anlamsızken, uzun dönemde pozitif ve anlamlıdır. Azam ve Khan (2015) çalışmasında, Sri Lanka için kentleşme ve çevresel bozulma arasında pozitif ilişki tespit etmiştir. Buna göre çalışmada artan kentsel nüfus nedeniyle, altyapı, enerji ve ulaşım araçlarının kullanımının artması ile tarımdan sanayi sektörüne geçişin çevre kirliliğini artırma nedenleri olarak sunulmuştur. Politika önerisi olarak tarım işletmelerinin faaliyetlerinin genişletilmesi, daha fazla ürün ve ağaç işlenmesi teklif edilmiş bu sayede daha fazla oksijen seviyesi elde edileceği ve atmosferde daha düşük CO2 emisyonu sağlayacağı düşünülmüştür. Ayrıca, eğitim yoluyla halkın çevre bilincinin artırılması da gerekmektedir. Al-Mulali ve Öztürk (2015) Orta Doğu ve Kuzey Afrika'da yer alan 14 ülke için 1996-2012 döneminde çevresel bozulmanın nedenlerini araştırmışlardır. Pedroni Eşbütünleşme ve FMOLS testlerinin kullanıldığı çalışmada kentleşmenin çevresel bozulmayı artırdığı tespit edilmiştir. Kentleşme, bölgenin kirlilik yönetimi ve kontrolü için yeterince planlanmamıştır. Ayrıca şehir planlamasındaki politika yapıcılar, kentleşmenin yarattığı çevresel zararı azaltmaya yardımcı olabilecek bu kentleşme düzeylerini düşürmelidir. Pata (2018) Türkiye özelinde EKC hipotezinin varlı̆̆ını test ederek sanayileşme ve kentleşmenin karbon emisyonu üzerindeki etkisini incelemiştir. 1974-2013 dönemi verileri kullanılarak ARDL Sınır testinin kullanıldığ 1 bu çalışmada hem EKC varlığ 1 doğrulanmış hem de kentleşmenin karbon emisyonunu artırdığı sonucuna ulaşılmıştır. Katırcıoğlu ve Katırcıoğlu 
(2018) yılında Türkiye özelinde daha geniş bir veri kümesiyle 1960-2013 dönemi için Destek ve Özsoy (2015) ve Pata(2018) sonuçlarını destekleyen bulgulara işaret etmektedir. Ali vd.(2019) çalışmalarında Pakistan özelinde ARDL yöntemini kullanmışlardır. Hem kısa hem de uzun dönemde kentleşmenin çevresel bozulmayı artırdığı sonucuna ulaşılmıştır. Kentsel ulaşımda toplu taşımanın kullanılması, insanların çevresel konularda eğitimi ile bilinçlendirilmesi ve çevresel bozulmayı azaltacak devlet müdahaleleri politika önerileri olarak sunulmaktadır. Wang ve Dong(2019), 14 Sahra altı Afrika ülkesinde çevresel bozulma göstergesi olarak ekolojik ayak izinin kullanıldığı çalışmada kentleşme ve yenilenebilir enerji kullanımının etkisi incelenmiştir. Buna göre çevresel bozulmayı kentleşmenin artırdığı buna karşılık yenilenebilir enerjinin azalttı̆̆ sonucuna ulaşılmıştır. Bu nedenle, kentsel plancilar ve tasarımcların kentsel gelişimi planlarken çevreyi dikkate almaları gerektiği vurgulanmıştır.

Kentleşme ve çevresel bozulma arasında doğrusal olmayan ilişkilerin tespit edildiği üçüncü grup çalışmalardan Martinez-Zarzoso ve Maruotti (2011) gelişmekte olan ülkelerde kentleşme ve CO2 emisyonları arasındaki ilişkiyi araştırmaktadır. Sonuç, kentleşme ve karbon emisyonları arasında ters çevrilmiş U şeklinde bir ilişki olduğunu ortaya koymaktadır. Bu sonucun çok önemli bir politika etkisi vardır: bazı ülkeler için kentleşme belli bir düzeye ulaştığında, emisyonlar üzerindeki etki negatif olur ve çevresel zararın azalmasına katkıda bulunur. Sosyologlar tarafından geliştirilen ekolojik modernleşme teorisini doğrulayan bulgulara dikkat çekilmektedir. Wang vd. (2015) ise OECD ülkelerinde yarı parametrik panel sabit etkileri regresyonu kullanmışlardır. Çevresel Kuznet Eğrisinin doğrulandığı çalışmada kentleşmenin çevresel bozulmayı önce artırdığı, belli bir eşikten sonra ise çevresel bozulmada düşüş gerçekleştiği görülmektedir. Bu durum kentleşmenin karbon emisyonu çözümünün bir parçası haline gelebileceği öngörmektedir. Shahbaz vd. (2016) 1970-2011 Malezya örneğinde kentleşmenin başlangıçta CO2 emisyonlarını azalttığını, ancak bir eşik seviyesinden sonra CO2 emisyonlarını artırdığını tespit etmiştir. Nedensellik analizi, Granger kentleşmesinin CO2 emisyonlarına neden olduğunu göstermektedir. Çalışmada sonuçlara ilişkin politika önerileri sunulmuştur. İrfan ve Shaw (2017) Güney Asya ülkeleri olan Hindistan, Pakistan ve Bangladeş olmak üzere seçilen üç ülkenin ele alındığı bir panel çalışması yapmıştır. Ülke ve zamana özgü sabit etkilerle parametrik olmayan katkı modeli kullanılarak ilişki araştırılmıştır. Sonuçlar 
kentleşme düzeyinin, karbondioksit emisyonları ile U şekilli ilişkiyi tersine çevirdiğini göstermektedir. Kentleşmenin çevre kirliliği üzerindeki etkilerine ilişkin olarak, çevresel zararların kentleşmenin artmasıyla bir eşiğe yükseldiğini, ancak bundan sonra, bölgenin her üçünde de nispeten planlanmış ve düzenlenmiş şehirleşme nedeniyle çevresel zararların düştügünü göstermektedir. $\mathrm{Bu}$, bölgedeki yeni tasarlanmış çevre politikaları nedeniyle doğrudur. Endüstriler artık kirliliği azaltma teknolojilerini uygulamaktadır, dizel yakıtla çalışan eski araçların kentsel alanlarda çalışması kısıtlanmıştır ve ülkelerde yeni ilçeler sürekli gelişmekle birlikte planlamalar çevresel zararları azaltmaya yöneliktir. Muhammad vd.(2020), 65'den fazla Kuşak ve Yol Girişimi ülkelerinin ele alındığı 2000-2016 dönemini kapsayan bu çalışmada İki Aşamalı En Küçük Kareler Yöntemi kullanılmış ve kentleşme ile çevresel bozulma arasında yüksek gelirli ülke grubunda doğrusal olmayan bir ilişki tespit edilmiştir. Bu ülke grubu için modernleşme teorisi doğrulanmaktadır. Kentleşmenin ilk aşamasında, yüksek enerji girişi gerektiren ve karbondioksit emisyonların artıran karayolu, köprüler vb. gibi birçok altyapının inşa edilmesi gerekmektedir. Kalkınmanın daha sonraki bir aşamasında, kentleşme teknolojik süreç, katı hükümet politikaları, bilgi yayılması, toplumsal farkındalık ve gelişmiş enerji yapısı yoluyla karbon emisyonlarını azaltma eğilimindedir.

Dördüncü grup çalışmalardan Sharif (2012), ekonomik kalkınma nedeniyle Japonya'da kırsal nüfus kentsel alana göç etmekte, bunun sonucunda kentsel nüfusun kentsel kaynaklar ve çevre üzerinde baskı yaratması dolayısıyla çevre kirlenmektedir. Dolayısıyla, kentleşmenin çevresel kirlilik üzerindeki etkisinin önemli olup olmadığının bilinmesi, bu ampirik çalışma için düşünülmektedir. Elde edilen sonuca göre 1960-2009 döneminde kentleşmenin çevresel bozulma üzerindeki etkinin anlamsız olduğu tespit edilmiştir. Sadorsky (2014) 16 gelişmekte olan ülke için 1971-2009 döneminde kentleşmenin $\mathrm{CO} 2$ emisyonu üzerindeki etkisini incelemiştir. Hem statik hem de dinamik panel veri yöntemlerinin kullanıldığ bu çalışmada çoğu modelde kentleşmenin çevresel bozulmayı artırdığı bulunmuş fakat bu etkinin anlamsız olduğu ifade edilmiştir. Elde edilen bulgulardan hareketle sürdürülebilir kalkınma politikaları ve karbon emisyonu azaltma stratejileri açısından kentleşme değişkeninin dikkate alınmaması sonuçlar üzerinde hemen hemen etki oluşturmayacaktır. Bu çalışmanın sonuçları, kentleşmenin CO2 emisyonları 
üzerindeki iki karşıt etkisinin, $\mathrm{CO} 2$ emisyonları üzerindeki net etkisini istatistiksel olarak sıfırdan büyük bırakarak birbirini iptal etme eğiliminde olduğunu göstermektedir.

\section{Data Setinin Tanımlanması ve Metodoloji}

Bu çalışmada 1960-2014 döneminde Türkiye'de ekonomik büyüme ve kentleşmenin çevresel bozulma üzerine etkileri incelenmiştir. Çevre kirliliği göstergesi olarak karbon emisyonu, ekonomik büyüme göstergesi olarak kişi başı GSYH ve kentleşme göstergesi olarak ise kentsel nüfus değişkeni kullanılmıştır. $\mathrm{CO}_{2}$ emisyonu kişi başı metrik ton olup, fosil yakıtların yakılmasından ve çimento üretiminden kaynaklanan emisyonlardır. GSYH verisi sabit verilerle 2010 \$ USD ile gösterilmektedir. Tüm değişkenler Dünya Bankasından alınmıştır. Çalışmada kentleşme ve ekonomik büyümenin çevresel bozulma üzerindeki etkisi ARDL modeli ile tahmin edilmiş olup, nedensellik ilişkisi de ECM'ye dayalı Granger nedensellik ile tespit edilmiştir.

Değişkenler arasındaki uzun dönemli ilişkinin tespiti için Gecikmesi Dağıtılmış Otoregresif Modeline (ARDL) dayalı sınır testi kullanılmaktadır. Engle-Granger (1987) ile Johansen (1988) kointegrasyon testlerinde denklemdeki bütün değişkenlerin farkı alındığında durağanlaşmaları varsayımı koşulunda eşbütünleşme ilişkisi test edilmektedir. Kointegrasyon analizi ile tahmin yapılabilmesi için zorunlu olan bu özellik Pesaran ve Pesaran (1997) ile Pesaran vd. (2001)'nin çalışmalarıyla literatüre kazandırılan ARDL analizi ile zorunlu olmaktan çıkmıştır. ARDL Sınır testinin diğer kointegrasyon testlerine göre avantajları vardır. Bunlardan birincisi, kurulan modeldeki değişkenlerin sırasıyla birinci farkta durağan ve seviyede durağan olduğunda da analize uygun olmasıdır. İkinci üstünlüğü, kısıtsız hata düzeltme modeli(ECM) ile daha anlamlı sonuçları sağlaması ve küçük örneklemli çalışmalarda güvenilirliğinin daha çok olmasıdır(Narayan ve Narayan, 2005: 429). Çalışmamızda sahip olunan avantajlar ile değişkenlerin durağanlık durumu nedeni ile ARDL analizi tercih edilmektedir. 1 ve 2 nolu modellerde ARDL modeline ilişkin, değişkenler kullanılarak oluşturulan eşitlikler verilmektedir. $\theta$ katsayıları bağımsız değişkenlere ait olan katsayı matrisini temsil etmektedir. $k, 1$ ve $\mathrm{m}$ ise serilerin alabileceği farklı gecikme sayılarını temsil et- 
mektedir. i sembolü gecikme sayısını gösterirken; et ise modeldeki artık terimi ifade etmektedir. Modeldeki gecikme sayıları Akaike Bilgi Kriteri (AIC) yardımıyla belirlenmiştir.

$$
L c_{t}=\theta_{0}+\sum_{i=1}^{k} \Theta_{1 i} L g_{t-i}+\sum_{i=0}^{l} \Theta_{2 i}(L g) 2_{t-i}+\sum_{i=0}^{m} \theta_{3 i}(L k)_{t-i}+e_{t}
$$

Model belirlendikten sonraki aşamada sınır testinde kullanılacak eşitlik oluşturulacaktır. Aşağıdaki eşitlik kullanılarak değişkenler arasındaki uzun dönemli ilişkilerin analizi ortaya konmaktadır.

$$
\begin{aligned}
\Delta L c_{t}=\boldsymbol{\theta}_{0}+\sum_{i=1}^{k} & \boldsymbol{\theta}_{1 i} \Delta L g_{t-i} \\
& +\sum_{\substack{i=0\\
}}^{l} \boldsymbol{\theta}_{2 i} \Delta(L g) 2_{t-i}+\sum_{i=0}^{m} \theta_{3 i} \Delta L k_{t-i}+\boldsymbol{\theta}_{4} L g_{t-i} \\
& +\boldsymbol{\theta}_{5}(L g) 2_{t-i}+\boldsymbol{\theta}_{6} L k_{t-1}+e_{1 t}
\end{aligned}
$$

Aşağıda CO2 emisyonu ile açıklayıcı değişkenler arasındaki eşbütünleşmenin test edilebilmesi için kurulan hipotezler vardır;

- $H_{0}: \theta_{4}=\theta_{5}=\theta_{6}=0$ (uzun dönemli ilişki yoktur),

- Hi: En az $\theta \neq 0$ (uzun dönemli ilişki vardır).

Hipotezler Wald $\mathrm{F}$ testi ile analiz edilmektedir. Wald $\mathrm{F}$ testi yardımıyla $\theta_{4}=$ $\theta_{5}=\theta_{6}=0$ katsayılarının eşanlı sıfıra eşit olup olmadığını gösteren istatistik değerleri elde edilmektedir. Pesaran vd. (2001, s.300) çalışmasından bulunan alt sınır I(0) ve üst sınır I(1) değerleri hesaplanan istatistik değeri ile karşılaştırılmaktadır. Hesaplanan değer üst sınır kritik değerinden büyük olduğunda $\mathrm{Ho}$ reddedilmez, bu da değişkenler arasındaki uzun dönemli ilişkiyi doğrular. ARDL modelinin sağlamlığı bazı teşhis testleri ile kontrol edilmiştir. Teşhis testleri otokorelasyonu, fonksiyonel formu, hata teriminin normalliğini ve heteroskedastisitesini kontrol eder.

$$
\begin{aligned}
\Delta L \mathrm{c}_{t}=\boldsymbol{\theta}_{0}+\sum_{i=1}^{k} & \boldsymbol{\theta}_{1 i} \Delta L \mathrm{~g}_{t-i} \\
& +\sum_{i=0}^{l} \boldsymbol{\theta}_{2 i} \Delta(L g) 2_{t-i}+\sum_{i=0}^{m} \theta_{3 i} \Delta L k_{t-i}+\boldsymbol{\theta}_{4} e \mathrm{~cm}_{t-1}+e_{1 t}
\end{aligned}
$$


Değişkenler arasındaki eşbütünleşme ilişkinin varlığı sebebi ile nedensellik durumuna karar vermek için ECM-Based Granger Nedensellik test edilmektedir. Bağımsız değişkenlerden $\mathrm{CO}^{\prime}$ ye doğru elde edilen anlamlı eşbütünleşme ilişkinin varlığ 1 değişkenler arasında nedensellik ilişkilerinin olabileceği konusunda ipucu vermektedir. Bu çalışmada Granger (1969) tarafından geliştirilen nedensellik testi temel alınarak Bağımsız değişkenlerden CO2'ye doğru kısa ve uzun dönemli nedensellik ilişkilerin varlı̆̆ araştırılmaktadır. Değişkenler arasında eşbütünleşme ilişkisi olmasından dolayı hata düzeltme eşitliği yardımıyla nedensellik ilişkileri test edilmektedir. Aşağıdaki hipotezler vasıtasıyla kısa dönemde nedensellik ilişkisinin varlığı belirlenmektedir.

- $H_{0}: \boldsymbol{\theta}_{1 i}=0, \boldsymbol{\theta}_{2 i}=0, \boldsymbol{\theta}_{3 i}=0$ ( Lg ve (Lg)2 ile lk'dan Lc'ye doğru kısa dönemli nedensellik yoktur),

- $H_{1}: \boldsymbol{\theta}_{1 i} \neq 0, \boldsymbol{\theta}_{2 i} \neq 0, \boldsymbol{\theta}_{3 i} \neq 0$ ( $L g$ ve ( $\mathrm{Lg}$ )2 ile lk'dan Lc'ye doğru kısa dönemli nedensellik vardır).

Uzun dönemli nedensellik ilişkisinin varlığ $\left(\boldsymbol{\theta}_{4}\right)$ sıfıra eşit olup olmadığının test edilmesiyle belirlenmektedir. Burada katsayılara kısıt testi (F testi) uygulanarak bu hipotezler test edilmektedir.

\section{Ampirik Bulgular}

Zaman serisi analizinde değişkenler arasında bir ilişkinin varlığı ve ilişkinin yönünün ne olacağı ile ilgili analizi belirlemeden önce durağanlık analizlerinin yapılması gerekmektedir. Aşağıdaki tabloda öncelikle değişkenlerin tanımlayıcı istatistikleri sunulmaktadır. Bu istatistiklere göre değişkenlerle ilgili herhangi bir problem söz konusu değildir. Değişkenlere ait grafikler dikkate alındığında verilerde trend olduğu görülmektedir. Bu sebeple birim kök testleri uygulandığında trendli modellere itibar edilecektir. CO2 emisyonu, GSYH ve Kentleşme 'ye ait birim kök test sonuçları aşağıda verilmektedir

Tablo 1. Tanımlayıcı İstatistik

\begin{tabular}{lllllllll}
\hline Variable & Obs & $\begin{array}{l}\text { Unit of Me- } \\
\text { asurement }\end{array}$ & Mean & Std.Dev. & Min & Max & Skewness & Kurtosis \\
\hline LC & 55 & Logaritmik & 0.7548 & 0.5482 & -0.49 & 1.49 & -0.6215 & 2.4333 \\
LKG & 55 & Logaritmik & 8.736 & 0.3887 & 8.05 & 9.49 & 0.0897 & 2.1136 \\
LK & 55 & Logaritmik & 39.361 & 0.2713 & 3.45 & 4.29 & -0.3229 & 1.6437 \\
\hline
\end{tabular}


LC
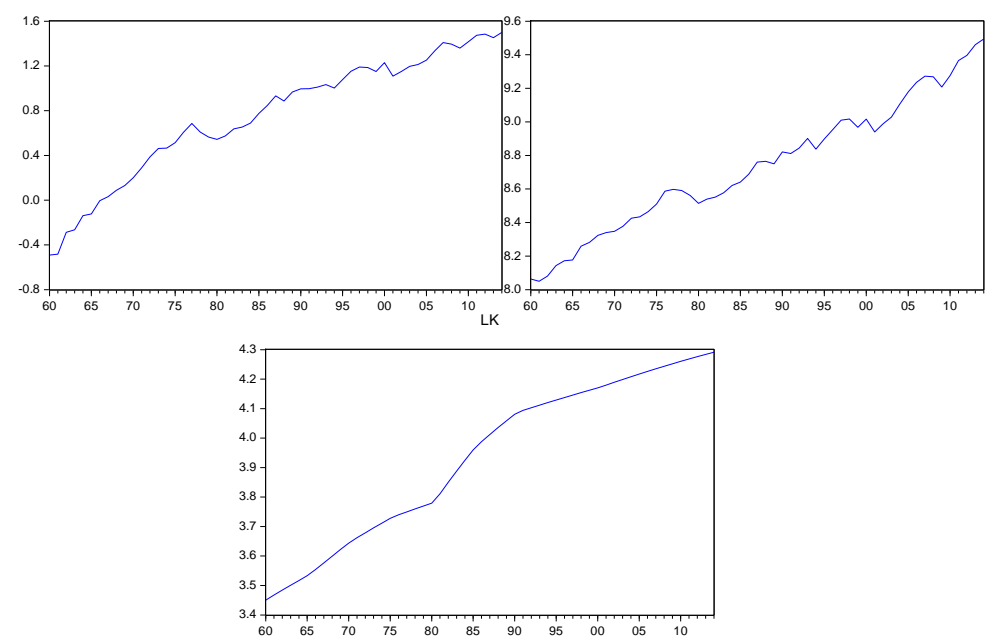

Grafik 1. LC, LKG ve LK için Grafik Çizimleri

Tablo 2. Tek Kırılmalı ADF Test Sonuçları

\begin{tabular}{|c|c|c|}
\hline Variable & Calculated t-statistic & Breaking Date \\
\hline LC & -3.1087 & 1979 \\
\hline LKG & -3.6575 & 1978 \\
\hline LK & $7.4391^{* * * *}$ & 1980 \\
\hline$\Delta \mathrm{LC}$ & $-8.9410^{* * * *}$ & 1981 \\
\hline$\Delta \mathrm{LKG}$ & $-6.8130^{* * *}$ & 2002 \\
\hline$\Delta \mathrm{LK}$ & - & - \\
\hline
\end{tabular}

Uygulanan kırılmalı ADF testinin $\mathrm{H} 0$ hipotezi birim kök vardır. CO2 emisyonu ve GSYH değişkenleri birinci farkı alındığında durağandır. Buna karşılık kentleşme değişkeninin seviyede durağan olduğu tespit edilmiştir. Değişkenlerin durağanlığının ortaya konulması ile uzun dönemli ilişkinin durumunu incelemek üzere ARDL sinır testi uygulanmaktadır. Yapılan analiz uygun model olarak ARDL $(1,4,0,1)$ modelini göstermektedir. Aşağıda oluşturulan modelde herhangi bir problemin olup olmadığını incelemek için tanısal testler uygulanmıştır. Tablo 4 bu modelde otokorelasyon, değişen varyans sorunları ile karşılaşılmadığını ve hata terimlerinin de normal dağıldığına işaret etmektedir. 
Tablo 3. ARDL Modeli

\begin{tabular}{lllll}
\hline LC(-1) & 0.336219 & 0.147368 & 2.281488 & 0.0279 \\
LKG & 7.541144 & 2.187818 & 3.446880 & 0.0013 \\
LKG(-1) & -0.206510 & 0.211944 & -0.974361 & 0.3357 \\
LKG(-2) & -0.011532 & 0.162709 & -0.070877 & 0.9438 \\
LKG(-3) & 0.092621 & 0.161049 & 0.575110 & 0.5684 \\
LKG(-4) & 0.175483 & 0.147691 & 1.188173 & 0.2418 \\
LKGG & -0.369292 & 0.120509 & -3.064438 & 0.0039 \\
LK & 1.394290 & 0.703292 & 1.982518 & 0.0543 \\
LK(-1) & -1.003863 & 0.679712 & -1.476895 & 0.1475 \\
C & -38.77556 & 11.05273 & -3.508233 & 0.0011 \\
@TREND & -0.011868 & 0.005983 & -1.983394 & 0.0542 \\
\hline
\end{tabular}

ARDL $(1,4,0,1)$ modelinde katsayıların istikrarlılının testi ise CUSUM testleri ile denetlenmiştir. Elde edilen bulgulara göre $\% 5$ anlamlllık seviyesinde değişkenlerde herhangi bir yapısal kırılmanın olmadığı ve istikrarlı olduğu bulunmuştur. Tablo 5' e göre GSYH ve GSYH değerinin karesi ile kentleşmenin $\mathrm{CO}_{2}^{\prime}$ yi etkilediği sonucu doğrulanmaktadır. Yani değişkenler arasında uzun dönemde bir ilişki söz konusudur. Tablo 6'daki sonuçlar dikkate alındığında ECM katsayısının istatistiksel olarak anlamlılığı söz konusudur. ECM katsayısının 0 ile -1 değerleri aralığında olması hata düzeltme sürecinin uzun dönem dengesine monoton olarak yakınsadığı anlamına gelmektedir. Bununla birlikte kısa dönem katsayıları dikkate alındığında bağımsız değişkenlerin bağımlı değişken üzerinde anlamlı olduğu görülmektedir. Uzun dönemde katsayıları incelendiğinde ise gerek GSYH ile gerekse kentleşme değişkenlerinin $\mathrm{CO} 2$ emisyonu üzerinde anlamlı bir etkisinin olduğu görülmektedir. Ekonomik büyüme ile karbon emisyonu arasında doğrusal olmayan (non-lineer) bir ilişki gözükmektedir. Bu bağlamda ekonomik büyüme ile çevresel bozulma arasındaki ilişki Çevresel Kuznet eğrisini doğrulamaktadır. Ekonomik büyümenin ilk aşamalarında $\mathrm{CO} 2$ değeri artmakta daha sonra ise azalmaktadır. Kentleşmenin ise çevresel bozulmayı artırdığı sonucuna ulaşılmıştır.

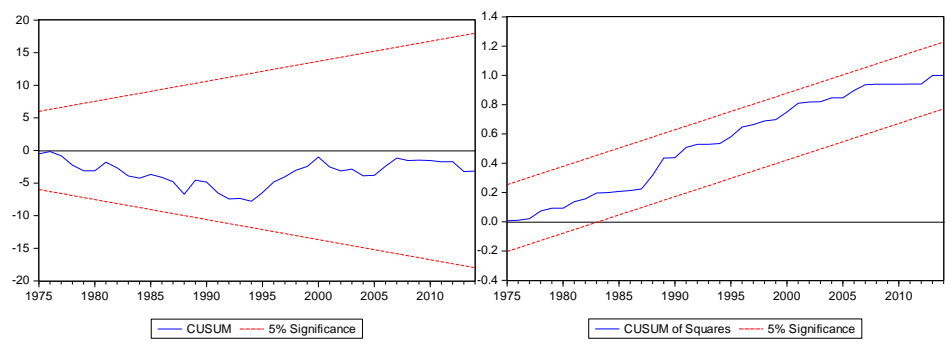


Tablo 4. Tanisal Testler

\begin{tabular}{lll}
\hline Test & Hesaplanan İstatistik & Olasılık \\
\hline Breusch-Godfrey Otokorelasyon & 0.184 & 0.782 \\
\hline Breusch-Pagan-Godfrey Değişen Varyans & 0.897 & 0.543 \\
\hline Jargue-Bera Normalillik & 0.480 & 0.786 \\
Ramsey & 0.124 & 0.726 \\
\hline
\end{tabular}

Tablo 5. ARDL Sınır Testi Sonuçlan

\begin{tabular}{lll}
\hline Test & F İstatistiği & \%5 Kritik değerler \\
\hline Sınır Testi & 5.03 & $3.38-4.23$ \\
\hline
\end{tabular}

Tablo 6. Kısa Dönem ve Uzun Dönem Katsayıları

\begin{tabular}{lllll}
\hline \multicolumn{4}{l}{ Kisa Dönem Katsayıları ve Hata Düzeltme Modeli } & \\
\hline Değişken & Katsayı & Standart Hata & t-istatistik & Olasılık \\
\hline D(LKG) & 7.626626 & 2.751241 & 2.772067 & 0.0084 \\
D(LKG(-1)) & -0.255381 & 0.125631 & -2.032777 & 0.0487 \\
D(LKG(-2)) & -0.267646 & 0.121247 & -2.207443 & 0.0331 \\
D(LKG(-3)) & -0.175214 & 0.120385 & -1.455453 & 0.1533 \\
D(LKGG) & -0.374108 & 0.154085 & -2.427928 & 0.0198 \\
D(LK) & 1.384152 & 0.578338 & 2.393327 & 0.0215 \\
C & -38.669030 & 7.647332 & -5.056538 & 0.0000 \\
CointEq(-1) & -0.661757 & 0.130876 & -5.056346 & 0.0000 \\
Uzun Dönem Katsayıları & & & \\
\hline Değişken & Katsayı & Standart Hata & t-istatistik & Olas1lık \\
\hline LKG & 11.436308 & 1.841222 & 6.211260 & 0.0000 \\
LKGG & -0.556346 & 0.106275 & -5.234941 & 0.0000 \\
LK & 0.588187 & 0.276982 & 2.123560 & 0.0399 \\
@TREND & -0.017879 & 0.008288 & -2.157078 & 0.0371 \\
\hline
\end{tabular}

*\%5 anlamlllk düzeyine göre anlamlllğı ifade etmektedir.

Tablo 7. ECM'ye Dayalı Granger Nedensellik Test Sonuçları

\begin{tabular}{|c|c|c|c|c|c|}
\hline $\begin{array}{l}\text { Nedensellik } \\
\text { Dönemleri }\end{array}$ & $\begin{array}{l}\text { Kisa } \\
\text { Dönem }\end{array}$ & & & & $\begin{array}{l}\text { Uzun } \\
\text { Dönem }\end{array}$ \\
\hline Bağımlı Değişken & $\Delta L C$ & $\triangle L G D P$ & $\triangle L G D P P$ & $\triangle L K E N T$ & $\mathrm{ECM}(-1)$ \\
\hline$\Delta L C$ & - & $\begin{array}{l}7.67^{* * * *} \\
(0.0083)\end{array}$ & $\begin{array}{c}5.88^{* *} \\
(0.0196)\end{array}$ & $\begin{array}{c}5.72^{* *} \\
(0.0212)\end{array}$ & $\begin{array}{l}25.56^{* * * *} \\
(0.0000)\end{array}$ \\
\hline
\end{tabular}

******* Sirasıyla \%10,\%5,\%1 anlamlilık düzeyine göre anlaml nedensellik ilişkisini göstermektedir. Parantez içindeki değerler olasllk değerlerini göstermektedir.

Kısa dönemde tüm değişkenlerden $\mathrm{CO} 2$ emisyonuna doğru nedensellik olduğu görülmektedir. Hata Düzeltme katsayısı dikkate alındığında da tüm değişkenlerden $\mathrm{CO} 2$ ye doğru uzun dönemde nedensellik olduğu anlaşılmaktadir. 


\section{Sonuç ve Politika Önerisi}

Bu çalışmada Türkiye'de kentleşme ve ekonomik büyümenin çevresel bozulma üzerindeki etkisi 1960-2014 dönemi için incelenmiştir. Değişkenlerin özellikleri dikkate alındığında analiz için ARDL Sınır testi yaklaşımının uygun olduğu görülmüştür. Elde edilen sonuçlara göre uzun dönemde kentleşme ve ekonomik büyüme çevresel bozulma ile birlikte hareket etmektedir. Bir diğer açıdan hem kentleşme hem de ekonomik büyüme çevresel bozulmayı etkileyen 2 önemli faktördür. Uzun dönemde ekonomik büyüme ile çevresel bozulma arasında EKC doğrulanmıştır. Bu durum Türkiye ekonomisinde ekonomik büyümenin ilk safhada çevresel bozulmayı artırdığı, belli bir eşikten sonra ise çevresel bozulmanın azaldığı sonucunu göstermektedir. Kentleşmenin ise hem kısa dönemde hem de uzun dönemde çevresel bozulmayı artırıcı etkisi tespit edilmiştir. ECM'ye dayalı granger nedensellik test sonuçları ekonomik büyüme ve kentleşmeden çevresel bozulmaya hem kısa hem de uzun dönemde nedenselliğin olduğunu göstermektedir.

Bu sonuçlar çevresel politikalar açısından değerlendirildiğinde kentleşmenin önemli bir değişken olduğunu göstermektedir. Kentleşmenin $\mathrm{CO} 2$ emisyonlarını nasıl etkilediğinin daha iyi anlaşılması sürdürülebilir bir kalkınma perspektifinden gereklidir. Kentleşmenin $\mathrm{CO} 2$ emisyonları üzerinde olumlu ve istatistiksel olarak önemli bir etkisi olduğu tespit edilmesi tahmin modellerini ve iklim değişikliği politikasını etkileyecektir. Kentleşmenin CO2 emisyonları üzerindeki artırıcı etkisinin varlığı, bu durumu hesaba katmayan $\mathrm{CO} 2$ emisyon tahmin modellerinin hatalı tahmin edilmesine ve olması gerekenden daha az olmasina yol olacaktır. Türkiye ekonomisinde kentleşmenin çevresel bozulmaya neden olmasının ardında görülen nedenler olarak a)Yüksek kentleşmenin, daha yüksek ekonomik faaliyet ile ilişkili olması dolayısıyla daha yüksek ekonomik aktivite, daha fazla servet yaratır ve daha zengin bireyler genellikle karbondioksit emisyonlarını artırabilecek daha fazla enerji yoğun ürünlerin kullanılması b) Kentleşme ile birlikte kent nüfusu başına düşen orman alanı miktarı hızla azalmaktadır. Bu durumda ormanların atmosferden uzaklaştıracakları sera gazları artan kent nüfusuna karşın yetersiz kalması c) Kent nüfusunun talebini karşılamak için, yoğun tohumlama ve hibrit tohumların kullanımı toprak verimliliğini düşürürken karbondioksit emisyonlarının hızını artırması d) Planlanmamış ve düzensiz kentleşme e) Tarım 
sektöründen sanayi sektörüne geçiş f) Konut talebine bağlı olarak hatalı kentleşme, orman vb. doğal kaynakların gereksiz kullanılması görülebilir.

Söz konusu olumsuz etkiler çevre üzerinde baskı oluşturmaktadır. Farklı ekonomilerde daha yüksek bir kentleşme düzeyi, özellikle çevre bilincinin ve endişesinin zayıf olduğu ülkelerde çevresel bozulmayı teşvik edebilir. Buna karşın politika yapıcıların alması gereken önlemler belli bir eşiği yakalayana kadar gereklidir. Bu bağlamda öncelikle hanehalkı bilinçlendirilmeli, planlı ve organize kentleşme stratejisi ortaya konmalıdır. Çevre dostu malların üretimi ve tüketimi teşvik edilmeli, gerektiğinde sübvanse edilmelidir. Özellikle ölçek ekonomilerinden faydalanılacak biçimde ulaşım hizmetleri sağlanmalıdır. Sonuç olarak düşük karbon tüketimini sağlamak için kamu gerekli tedbirleri almalı ve çevre politikaları üretilirken ekonomik büyüme hedefinin gölgesinde bırakılmamalıdır. Yaşanabilir bir Türkiye ideali, güçlü ekonomi ve çevresel bozulmanın minimize olacağı temiz çevre ile eşanlı sağlanmalıdır. 


\title{
EXTENDED ABSTRACT
}

\section{Impact Of Economic Growth And Urbanization On Environmental Degradation: Evidence From Turkey}

\author{
Nurullah Altıntaş \\ Sakarya University
}

Urbanization emerges as one of the main issues that is increasing both in developing and developed countries and affects the economy. In Turkey, it can be seen that from the 1960s till today, the rate of urbanization has reached the level of seventy-five percent form thirty percent. In the wake of this increase in the rate of urbanization there is the desire for better education, job opportunities, more favorable health conditions and the desire for prosperity. However, the increase in urbanization has affected environmental conditions and resource use throughout the economy. With urbanization, an economic and social transformation leading to the physical development and expansion of urban areas takes place. Not only does the population move from rural areas to urban cities, but it also brings about the transformation from agricultural economy to the industry-based economy (Aydın ve Belli, 2018: 110). This is known to especially affect areas such as economic growth, energy consumption, unemployment and environmental degradation. As a result of urbanization, a process leading to increased energy demand and environmental degradation such as air pollution, reduction in forest areas, water pollution can occur. It is obvious that it will have a negative impact on environmental conditions in case of planning deficiency and poor administration in cities. On the other hand, with the increase in the level of welfare especially, awareness of environmental consciousness in economies dynamically, strict environmental policies of the state, progress in technology and improvement in environmental degradation are expected with environmentally friendly technology.

In this study, the situation of environmental degradation is questioned as a result of the increase in urbanization. However, an answer is sought for the question of how economic growth affects the environment. The impact of urbanization and economic growth on environmental degradation in Turkey's 
economy as a whole will be discussed with econometric methods for the period of 1960-2014. Based on the results obtained, the validity of the theory of urbanized environmental degradation in Turkey is questioned. In this sense, both the applied and the theoretical dimensions were evaluated together. Policy suggestions have been made in light of the results obtained. After this introduction, the study will be continued with applied literature, methodology and empirical results, and will be completed with conclusion and policy recommendations.

When the urbanized environmental degradation applied literature is examined, it is seen that there is no agreement in terms of the results obtained. Accordingly, it is seen that the studies are gathered in four different groups. The first of these is studies where urbanization reduces environmental degradation, secondly, studies where urbanization increases environmental degradation, and thirdly, studies finding the existence of a nonlinear relationship between urbanization and environmental degradation. Finally, outside these groups, there are also studies that find the relationship between the variables meaningless.

Ali, Abdul-rahim and Ribadu (2017) examined the effect of urbanization on $\mathrm{CO} 2$ emission in Singapore where the entire population lives in cities over the period 1970-2015 period. According to the results obtained, it has been observed that urbanization has a decreasing and important effect on environmental degradation. Therefore, urbanization will not be seen as an obstacle when initiating policies to be used to reduce environmental degradation in the country. Wang and Dong (2019) used the ecological footprint as an indicator of environmental degradation in 14 Sub-Saharan African countries, and the effect of urbanization and renewable energy use was investigated. A conclusion was reached that urbanization increases environmental degradation, whereas renewable energy decreases it. For this reason, it was emphasized that urban planners and designers should consider the environment when planning urban development. Muhammad et al (2020) in their study, covering the period of 2000-2016, in which more than 65 generations and Road Initiative countries were analyzed, Two-Stage Least Squares Method was used and a nonlinear relation was found to exist between urbanization and environmental degradation in high income country group. The modernization theory is confirmed for this country group. In the first stage of urbanization, infrastructures like roads, bridges, etc. that require high energy input 
thereby increasing carbon dioxide emissions needs to be constructed. At a later stage of development, urbanization tends to reduce carbon emissions through the technological process, strict government policies, information dissemination, social awareness and improved energy structure. Sharif (2012), Due to economic development, the rural population in Japan migrates to the urban area, as a result of which the urban population creates pressure on urban resources and the environment, and the environment is polluted. Therefore, knowing whether or not the impact of urbanization on environmental pollution is important is considered for this empirical study. According to the results obtained, the effect of urbanization on environmental degradation was found to be meaningless for the period of 1960-2009.

In this study, urbanization, economic growth and the impact on environmental degradation in Turkey were examined for the 1960-2014 period. Considering the characteristics of the variables, it was seen that the ARDL limit test approach is suitable for the analysis. According to the results obtained, urbanization and economic growth move together with environmental degradation in the long term. On the other hand, both urbanization and economic growth are two important factors affecting environmental degradation. In the long run, EKC has been verified between economic growth and environmental degradation. This situation shows that, economic growth in Turkey increases environmental degradation in its initial stage, and after a certain threshold the environmental degradation is reduced. On the other hand, it is found that urbanization increases environmental degradation both in the short term and long term. Granger causality test results based on ECM show that there is causality from economic growth and urbanization to environmental degradation both in the short and long term.

The following reasons can be considered as been behind urbanization in Turkey's economy causing environmental degradation; a) High urbanization, associated with higher economic activity, hence, higher economic activity, create more wealth and more wealthy individuals generally, use more energy-intensive products that can increase carbon dioxide emissions b) With urbanization, the amount of forest area per city population is rapidly decreasing. In this case, they are going to be deprived of forest atmosphere, greenhouse gases are insufficient against the increasing urban population c) To meet the demand of the urban population, the use of intensive seeding and 
hybrid seeds increases the speed of carbon dioxide emissions while decreasing soil fertility d) Unplanned and irregular urbanization e) Transition from the agricultural sector to the industrial sector $\mathrm{f}$ ) Incorrect urbanization due to housing demand leading to the unnecessary use of natural like the forest, etc.

These negative effects create pressure on the environment. A higher level of urbanization in different economies can promote environmental degradation, especially in countries where there is poor environmental awareness and concern. However, the measures that policymakers should take are necessary until they reach a certain threshold. In this context, firstly, household awareness should be raised and a planned and organized urbanization strategy should be put forward. Production and consumption of environmentally friendly goods should be encouraged and subsidized if necessary. Particularly, transportation services should be provided in such a way that benefits from economies of scale are possible. Consequently, the public should take the necessary measures to ensure low carbon consumption and economic growth target should not be made to overshadow environmental policies. Habitable Turkey with an ideal strong economy and a clean environment with minimized environmental degradation should be provided simultaneously.

\section{Kaynakça / References}

Adams, S., ve Klobodu, E. K. M. (2017). Urbanization, democracy, bureaucratic quality, and environmental degradation. Journal of Policy Modeling, 39(6), 1035-1051.

Al-Mulali, U., ve Ozturk, I. (2015). The effect of energy consumption, urbanization, trade openness, industrial output, and the political stability on the environmental degradation in the MENA (Middle East and North African) region. Energy, 84, 382-389.

Ali, H. S., Abdul-Rahim, A. S., ve Ribadu, M. B. (2017). Urbanization and carbon dioxide emissions in Singapore: evidence from the ARDL approach. Environmental Science and Pollution Research, 24(2), 1967-1974.

Ali, R., Bakhsh, K., ve Yasin, M. A. (2019). Impact of urbanization on CO2 emissions in emerging economy: evidence from Pakistan. Sustainable Cities and Society, 48, 101553. 
Aydin, A. ve Belli, A.(2018) Türkiye'de kentleşme politikası. Ed. E. Akman, C. Babaoğlu Türkiye'de Kentsel Alan ve Çevre Politikası Analizleri, Ekin Kitabevi Yayınları

Azam, M., ve Khan, A. Q. (2016). Urbanization and environmental degradation: Evidence from four SAARC countries - Bangladesh, India, Pakistan, and Sri Lanka. Environmental progress \& sustainable energy, 35(3), 823-832.

Belli A, Aydin, A.(2017). Kent kültürü ve kentlilik bilincinin oluşumunda üniversitelerin rolü: Mustafa Kemal Üniversitesi örneği. Akademik Sosyal Araștırmalar Dergisi, 39, 422-434

Destek, M. A., ve Ozsoy, F. N. (2015). Relationships between economic growth, energy consumption, globalization, urbanization and environmental degradation in Turkey. International Journal of Energy and Statistics, 3(4), 1550017.

Engle, R. F. ve Granger, C.V., (1987). Co-integration and error correction: representation, estimation, and testing. Econometrica: Journal of the Econometric Society, cilt(say1), 251-276.

Holden, E., ve Norland, I. T. (2005). Three challenges for the compact city as a sustainable urban form: household consumption of energy and transport in eight residential areas in the greater Oslo region. Urban studies, 42(12), 2145-2166.

Hossain, S. (2012). An econometric analysis for CO2 emissions, energy consumption, economic growth, foreign trade and urbanization of Japan. Low Carbon Economy, 3, 92-105

Irfan, M., ve Shaw, K. (2017). Modeling the effects of energy consumption and urbanization on environmental pollution in South Asian countries: a nonparametric panel approach. Quality \& Quantity, 51(1), 65-78.

Johansen, S., (1988). Statistical analysis of cointegration vectors. Journal of economic dynamics and control 12(2-3), 231-254.

Katircioğlu, S., ve Katircioğlu, S. (2018). Testing the role of urban development in the conventional environmental Kuznets curve: evidence from Turkey. Applied Economics Letters, 25(11), 741-746.

Martínez-Zarzoso, I., ve Maruotti, A. (2011). The impact of urbanization on CO2 emissions: evidence from developing countries. Ecological Economics, 70(7), 1344-1353.

Mol, A. P., ve Spaargaren, G. (2000). Ecological modernisation theory in debate: a review. Environmental politics, 9(1), 17-49. 
Muhammad, S., Long, X., Salman, M., ve Dauda, L. (2020). Effect of urbanization and international trade on $\mathrm{CO} 2$ emissions across 65 belt and road initiative countries. Energy, 196, 117102.

Narayan, P. K. ve Narayan, S., (2005). Estimating income and price elasticities of imports for Fiji in a cointegration framework. Economic Modelling, 22(3), 423-438.

Ozatac, N., Gokmenoglu, K. K., ve Taspinar, N. (2017). Testing the EKC hypothesis by considering trade openness, urbanization, and financial development: the case of Turkey. Environmental Science and Pollution Research, 24(20), 16690-16701.

Pata, U. K. (2018). The effect of urbanization and industrialization on carbon emissions in Turkey: evidence from ARDL bounds testing procedure. Environmental Science and Pollution Research, 25(8), 7740-7747.

Pesaran, M. H., ve Pesaran, B., (1997). Working with Microfit 4.0: interactive econometric analysis [Windows version]. Oxford University Press.

Pesaran, M. H., Shin, Y. ve Smith, R. J., (2001). Bounds testing approaches to the analysis of level relationships. Journal of applied econometrics, 16(3), 289326.

Sadorsky, P. (2014). The effect of urbanization on CO2 emissions in emerging economies. Energy Economics, 41, 147-153.

Saidi, K., ve Mbarek, M. B. (2017). The impact of income, trade, urbanization, and financial development on CO 2 emissions in 19 emerging economies. Environmental Science and Pollution Research, 24(14), 12748-12757.

Salahuddin, M., Gow, J., Ali, M. I., Hossain, M. R., Al-Azami, K. S., Akbar, D., ve Gedikli, A. (2019). Urbanization-globalization-CO2 emissions nexus revisited: empirical evidence from South Africa. Heliyon, 5(6), e01974.

Shahbaz, M., Sbia, R., Hamdi, H., ve Ozturk, I. (2014). Economic growth, electricity consumption, urbanization and environmental degradation relationship in United Arab Emirates. Ecological Indicators, 45, 622-631.

Shahbaz, M., Loganathan, N., Muzaffar, A. T., Ahmed, K., ve Jabran, M. A. (2016). How urbanization affects CO2 emissions in Malaysia? The application of STIRPAT model. Renewable and Sustainable Energy Reviews, 57, 83-93.

Wang, J., ve Dong, K. (2019). What drives environmental degradation? Evidence from 14 Sub-Saharan African countries. Science of the Total Environment, 656, 165-173. 
Wang, Y., Zhang, X., Kubota, J., Zhu, X., ve Lu, G. (2015). A semi-parametric panel data analysis on the urbanization-carbon emissions nexus for OECD countries. Renewable and Sustainable Energy Reviews, 48, 704-709.

\section{Kaynakça Bilgisi / Citation Information}

Altıntaş, N. (2020). Kentleşme ve ekonomik büyümenin çevresel bozulmaya etkisi: Türkiye örneği. OPUS-Uluslararası Toplum Araştırmaları Dergisi, 15(26), 4517-4539. DOI: 10.26466/opus.725429 